\title{
Investigations on the Nucleation Kinetics, Growth and characterization of Glycine Rubidium Chloride (GRC): a promising nonlinear optical single crystal
}

\author{
K. Lilly Mary Eucharista ${ }^{a^{*}}$, C. Krishnan ${ }^{\mathrm{b}}$ and P.Selvarajan ${ }^{\mathrm{c}}$ \\ ${ }^{a}$ Department of Physics, Sri MeenakshiGovt.Arts College for Women (Autonomous), Madurai - \\ 625 002. Tamil Nadu, India. \\ ${ }^{\mathrm{b}}$ Department of Physics, Arignar Anna College, Aralvoymoli-629301, Tamil Nadu, India \\ ${ }^{c}$ Department of Physics, Aditanar College of Arts and Science, Tiruchendur-628216, Tamil \\ Nadu, India.
}

\section{ABSTRACT}

Growth of Glycine Rubidium Chloride (GRC) single crystals were grown from aqueous solution by slow evaporation technique.Investigations on nucleation kinetic parameters are very important tools for the successful growth of good quality, transparent and big-sized single crystals. Glycine Rubidium salt was synthesized and solubility studies have been carried out by gravimetric method in the temperature range of $30-50{ }^{\circ} \mathrm{C}$. The induction period of the GRC salt for the selected super saturation ratio at room temperature was measured. The fundamental nucleation parameters such as Gibbs free energy change, interfacial tension, and critical radius, number of molecules in the critical nucleus and nucleation rate were calculated for GRC sample for the first time based on the classical theory of nucleation. The grown crystals were characterized by X-ray diffraction analyses. The important optical parameters such as absorption coefficient, extinction coefficient, refractiveindex, optical band gap, optical conductivity and electrical conductivity were estimated from UV-vis-NIRspectral analysis to study the linear optical behavior of the material. Fourier transform infrared (FTIR) study was used to confirm the presence of various functional groups in the grown crystal. The TG and DTA analyses ensure that the material is thermally stable up to $222^{\circ} \mathrm{C}$. The hardness parameters such as microhardness number, work hardening coefficient, yield strength and elastic stiffness constant of the grown GRC crystals were calculated from microhardness studies. Second harmonic efficiency (SHG) of the grown material is 1.1866 times as that of KDP crystal. The third-order nonlinearities of GRC crystal have been investigated by Z-scan method. The values of nonlinear refractive index $\left(\mathrm{n}_{2}\right)$, 
the nonlinear absorption coefficient $(\beta)$ and third-order nonlinear susceptibility $(\chi(3))$ are estimated for the sample.

Keywords: Nucleation kinetics, Solution growth, XRD, Transmittance, Single crystal,Nonlinear optical material

*Corresponding author

Tel: +919487521632

E-mail address: lilly.mary@ymail.com (K. Lilly Mary Eucharista)

\section{Introduction}

Recent research is focused on the search for suitable materials displaying excellent nonlinear optical (NLO) properties for potential applications in optoelectronics, and optical storage device [1,2]. Amino acids are interesting materials for NLO application [3, 4]. Many numbers of natural amino acids are individually exhibiting the nonlinear optical properties because they are characterized by chiral carbons, a proton-donating carboxyl (-COOH) group and the proton accepting amino $\left(\mathrm{NH}_{2}\right)$ group [5-8]. The crystal structures of amino acids and their complexes have provided a wealth of interesting information to the patterns of their aggregation and the effect of other molecules and ions on their interactions and molecular properties [9].

Glycine is the smallest of the amino acids. Complexes of amino acids with inorganic salts are promising materials for optical second harmonic generation (SHG), as they tend to combine the advantages of the organic amino acid with that of the inorganic salt [10].Glycine molecule can exist in zwitterionic form and hence it is capable of forming compounds with anionic, cationic and neutral chemical compounds. Thus a large variety of glycine coordinated compounds can be formed [11]. The family of organic or semi organic amino acids shows interesting NLO properties [12,13].The semi-organic crystals have some advantages such as higher second order optical non-linearities, short transparency cut-off wavelength and stable physico-chemical performance over the traditional inorganic and organic crystals [14,15]. Since there is a large demand for crystal because of the revolution in electronic industries, it is required to synthesize new NLO materials and improve the properties of the existing materials.In this work, the growth, synthesis and nucleation kinetics, X-ray diffraction studies, SHG, Thermal analysis studies, UV-visible transmittance studiesof glycine rubidium chloride by slow evaporation method from aqueous solution were reported. 


\section{Experimental procedure}

\subsection{Synthesis and solubility}

The starting materials were of analytical reagent, and the synthesis and growth process were carried out in aqueous solution.GRC compound was synthesized by taking Glycine and Rubidium chloride in a 2:1 stoichiometric ratio. The calculated amounts of glycine and rubidium chloride were dissolved in the deionized water. The prepared solution was left to dryness at room temperature. Purity of the synthesized salt was improved by successive recrystallization process. Optically transparent and defect free seed crystals of GRC obtained by slow evaporation technique were for bulk growth. Solubility is defined as the amount of solute in grams present in $100 \mathrm{ml}$ of saturated solution at a particular temperature and provides a driving force for both nucleation and crystal growth. The solubility study was carried out for the GRC salt in double distilled water by gravimetrical method $[16,17]$. Initially, solubility was determined at $30^{\circ} \mathrm{C}$ by dissolving the solute in $25 \mathrm{ml}$ of double distilled water in an airtight container maintained at a constant temperature with continuous stirring using magnetic stirrer. GRC salt was added in small amount at successive stages and then the solute was added till a small precipitate was formed. This gave a confirmation of the super saturated condition. Then the $5 \mathrm{ml}$ of the saturated solution was pipetted out and taken into a petri dish of known weight and it was heated till the solvent was evaporated. The amount of the salt present in $5 \mathrm{ml}$ of the solution was measured by subtracting the empty petri dish's weight. From the above value, the amount of the salt present in $100 \mathrm{ml}$ of the solution was found out. The same procedure was followed for the temperatures 30 , $35,40,45$ and $50^{\circ} \mathrm{C}$. The solubility diagram of the GRC salt is displayed in figure1.

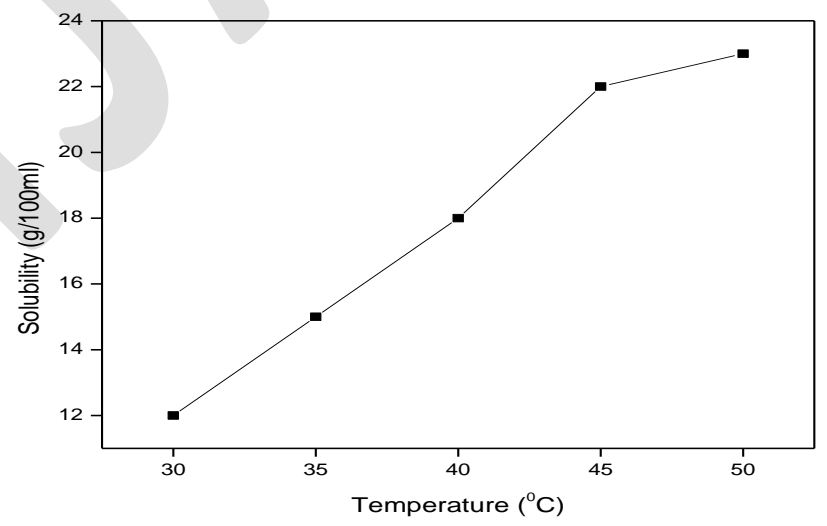

Fig .1.Solubility curve of GRC crystal 


\subsection{Metastable zone width studies}

Metastable zone width depends on stirring rate, cooling rate of the solution and presence of additional of impurities. GRC solution was prepared according to the solubility data. The recrystallized salt was added to $100 \mathrm{ml}$ of deionized water taken in beaker. The solution was stirred continuously using magnetic stirrer and saturated at $30^{\circ} \mathrm{C}$. The temperature of the solution was raised to $5^{0} \mathrm{C}$ above the saturated temperature. From this preheated temperature the solution was cooled until the first visible crystal nucleus appear. Since the time taken for the formation of first visible nucleus after attainment of critical nucleus is very small, the first nucleus observed may be taken as critical nucleus. The direct vision method is used for studying the nucleation temperature. The difference between the saturated temperature and the nucleation temperature is taken to be the metastable zone width. The same procedure was repeated for various temperatures, 35, 40, 40 and $50^{\circ} \mathrm{C}$. The metastable zone width for different saturation temperatures is shown in figure 2 .

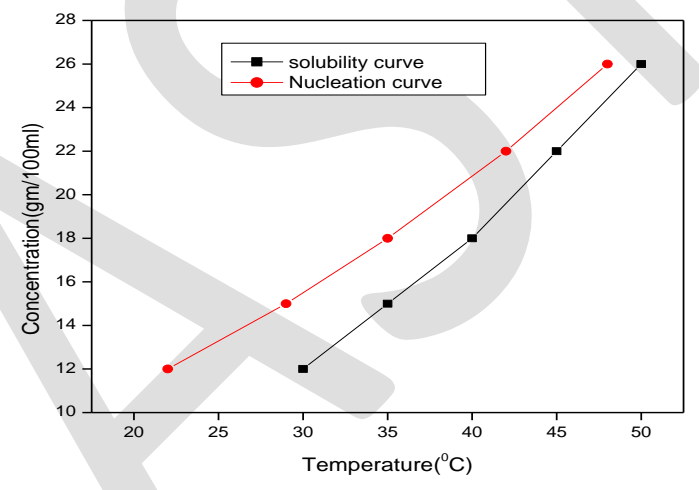

Fig.2. Metastable Zone width of GRC

\subsection{Induction Period}

Induction period of theGRC salt was measured by using isothermal method and direct vision observation method [18] for the different super saturation ratios. Induction period is defined as the time elapsed between theachievement of a supersaturated solution and the observation of first speck or tiny crystal.Super saturation concentration at a particular temperature was calculated using the relation

$$
\mathrm{C}=\mathrm{SC}_{0}
$$

Where $\mathrm{S}$ is the super saturation ratio and $\mathrm{C}_{0}$ is the saturated concentration. For $\mathrm{S}=1.1$, the induction period was measured when the appearance of first visible speck at the bottom of the 
container is noticed. The volume of the solution was taken as $10 \mathrm{ml}$ in the experiment. The consistency of the reading was verified by repeating the experiment two or three times. Similarly the induction period was carried out for $S=1.1,1.2,1.3,1.4,1.5$, and 1.6. Figure 3 shows the variation of induction period with supersaturation ratio for GRC. From figure (3), it is observed that the induction period decreases with increase in super saturation ratio[19]. The study of induction period against super saturation gives an idea of optimized induction period in order to have controlled nucleation rate to grow good quality single crystals.

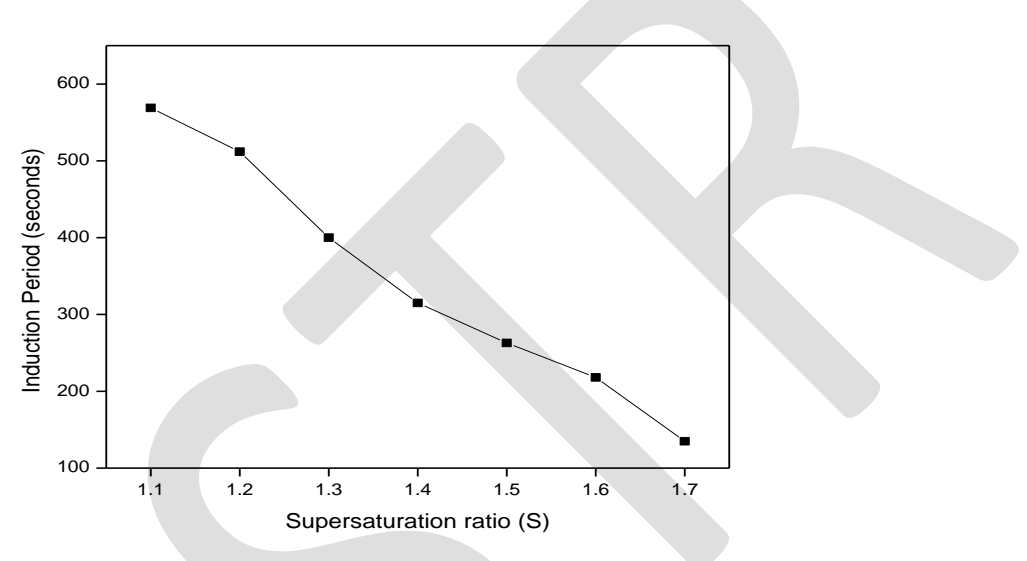

Fig.3. Induction period versus super saturation ratio for GRC crystal

\subsection{Nucleation Parameters}

Crystallization involves two distinct processes containingnucleation which is the birth of a nucleus and crystal growth which involves the subsequent growth of the existing nucleus. Nucleation is defined as the series of atomic or molecular processes by which the atoms or molecules of a reactant phase rearrange into a cluster of the product phaselarge enough as to have the ability to grow irreversibly to a macroscopically larger size. Nucleation can be classified into two types namely primary nucleation and secondary nucleation. Primary nucleation is further classified into homogeneous in the absence of foreign particles such us ions, impurity molecules, dust particles or surface of thecontainer and heterogeneous in the presence of foreign particles in the supersaturated solution. Secondary nucleation takes place when nucleation is induced by the presence of crystals of the same substance.

Nucleation kinetics depends on the thermodynamic driving force, which in turn depends on the super saturation, temperature and impurities present in the system. According to classical nucleation theory $(\mathrm{CNT})$, the free energy barrier to nucleation is called the Gibbs free energy 
change which consists of surface free energy and volume free energy. The change of Gibbs free energy is

$$
\Delta \mathrm{G}=\Delta \mathrm{G}_{\mathrm{v}}+\Delta \mathrm{Gs}
$$

Let the shape of the nucleus be spherical,

$$
\Delta \mathrm{G}=4 \pi \mathrm{r}^{2} \sigma+\frac{4}{3} \pi \mathrm{r}^{3} \Delta \mathrm{G}_{\mathrm{v}}(3)
$$

where $r$ is the radius of the nucleus and $\sigma$ is the interfacial tension or interfacial energy. The induction period in terms of Gibbs free energy is given by

$$
\ln \tau=-\mathrm{B}+\frac{\Delta G}{k T}(4)
$$

where B is a constant, $\mathrm{k}$ is a Boltzmann's constant and $\mathrm{T}$ is the absolute temperature. According to Thomson-Gibbs equation, the volume excess free energy is given by

$$
\Delta \mathrm{G}_{\mathrm{v}}=-\frac{\mathrm{kT}}{\mathrm{v}} \ln \mathrm{S}
$$

It is calculated for the different super saturation ratios. The Gibbs free energy will be maximum for a certain value of radius ( $\left.r^{*}\right)$ of nucleus, which is known as critical radius. A plot of $1 /(\ln S)^{2}$ against $\ln \tau$ forms a straight line as shown in figure 4 and interfacial energy is calculated from the slope using the equation

$$
\sigma=\mathrm{kT}\left[3 \mathrm{~m} / 16 \pi \mathrm{v}^{2}\right]^{1 / 3}
$$

The interfacial energy of the grown GRC crystal is found to be $0.9237 \times 10^{-3} \mathrm{~J} / \mathrm{m}^{2}$. The interfacial energy $\sigma$ of the interface between the growing crystal and the surrounding phase plays an important role in the nucleation of crystals.

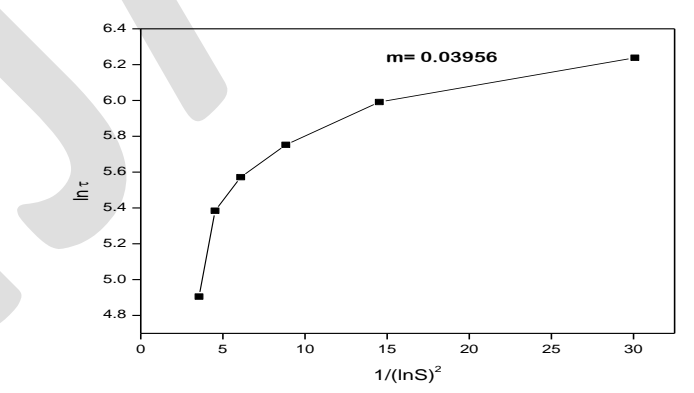

Fig.4.ln $\tau$ versus $1 /(\ln S)^{2}$ for GRC crystal

At the critical state

$$
\mathrm{d}(\Delta \mathrm{G} / \mathrm{dr})=0
$$

The radius of the critical nucleus ( $\left.\mathrm{r}^{*}\right)$, Gibbs free energy change $\left(\Delta \mathrm{G}^{*}\right)$ and number of molecules in the critical nucleus $(\mathrm{N})$ can be expressed as [20] 


$$
\begin{gathered}
\mathrm{r}^{*}=-2 \sigma / \Delta \mathrm{G}^{*} \\
\Delta \mathrm{G}^{*}=\mathrm{mkT} /(\ln \mathrm{S})^{2} \\
\mathrm{~N}=4 \pi\left(\mathrm{r}^{*}\right)^{3} / 3 \mathrm{v}
\end{gathered}
$$

Figure 5 shows the variation of critical nuclei at different super saturation ratios. The calculated radius of the critical nucleus varied between 2.1756 and $0.4397 \mathrm{~nm}$ as the super saturation was increased from 1.1 to 1.6 , and this nature is clearly shown in the graph. It can be asserted that as the super saturation is increased the size of the critical nuclei decreases.
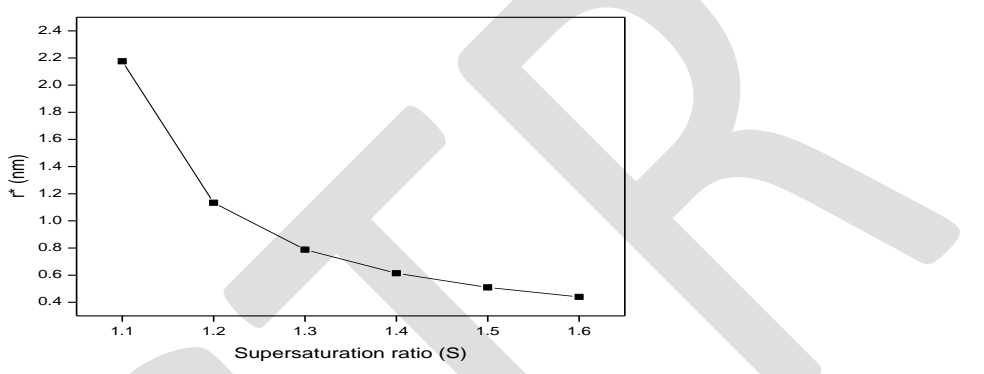

Fig.5. Critical radius versus super saturation ratio of GRC crystal

The number of crystals produced in the supersaturated solution is expressed as nucleation rate (J). It is defined as the number of crystals produced per unit volume per unit time and is given by

$$
\left.\mathrm{J}=\operatorname{Aexp}\left(-\Delta \mathrm{G}^{*}\right) / \mathrm{kT}\right)
$$

where $\mathrm{A}$ is the pre-exponential factor $\left(\sim 10^{30}\right.$ for solution) [21].Using the interfacial tension value, the radius of the critical nucleus, the Gibbs free energy change and nucleation rate were calculated for GRC crystal and presented in Table 1.From the table, it is noted that the increase in super saturation, the values of $r^{*}, \Delta G^{*}$ and $N$ except $J$ decreases. The response of the critical nucleation energy with varying super saturation is shown in Figure 6. This graph clearly shows that as the super saturation is increased the barrier to the nucleation considerably decreases, favoring the nucleation mechanism.

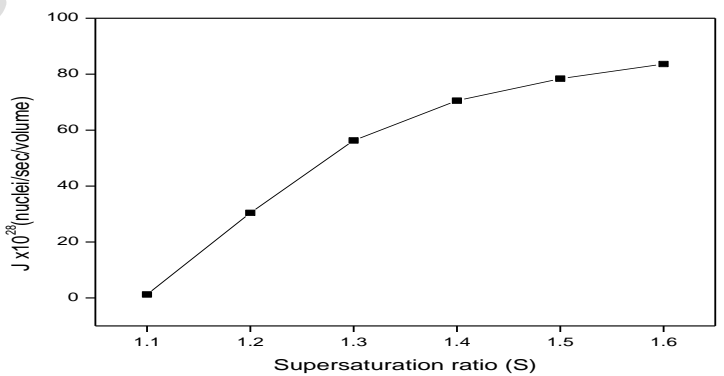

Fig.6. Critical free energy versus super saturation ratio of GRC crystal 
Table 1: Nucleation parameters of the GRC crystal

\begin{tabular}{|c|c|c|c|c|c|c|}
\hline Sample & $\mathrm{S}$ & $\begin{array}{l}\sigma \times 10^{-3} \\
\left(\mathrm{~J} / \mathrm{m}^{2}\right)\end{array}$ & $\begin{array}{c}\Delta \mathrm{G}^{*} \mathrm{x} 10^{-21} \\
\mathrm{~J}\end{array}$ & $\mathrm{r}^{*}(\mathrm{~nm})$ & $\mathrm{N}$ & $\begin{array}{c}\mathrm{J} \\
\text { (nuclei/sec/volume) }\end{array}$ \\
\hline \multirow{6}{*}{ BGRC } & 1.1 & \multirow{6}{*}{0.9237} & 18.31 & 2.1756 & 92.14 & $1.25 \times 10^{28}$ \\
\hline & 1.2 & & 4.97 & 1.1337 & 13.04 & $30.43 \times 10^{28}$ \\
\hline & 1.3 & & 2.40 & 0.7879 & 4.37 & $56.29 \times 10^{28}$ \\
\hline & 1.4 & & 1.46 & 0.6144 & 2.07 & $70.52 \times 10^{28}$ \\
\hline & 1.5 & & 1.01 & 0.5098 & 1.18 & $78.39 \times 10^{28}$ \\
\hline & 1.6 & & 0.74 & 0.4397 & 0.76 & $83.61 \times 10^{28}$ \\
\hline
\end{tabular}

\subsection{Growth of bulk GRC crystal}

Single crystals of GRC were grown by solution method with slow solvent evaporation technique. In accordance with the solubility and the nucleation kinetic data, saturated solution of the re-crystallized salt of GRC was prepared by dissolving the salt in de-ionized water by continuous stirring of the solution using a magnetic stirrer and the saturated solution was filtered using high quality Whatmann filter paper. The seed crystals of GRC were obtained by spontaneous nucleation. The super saturation of the solution was found by observing the first crystal formed at the bottom of the glass beaker due to slow evaporation of the solvent. The supersaturated solution was transferred into another beaker and kept at $30^{\circ} \mathrm{C}$. Two or three good quality seed crystals of GRC were placed in the supersaturated solution and the solution was allowed to evaporate. Well defined, transparent crystal of dimension $10 \times 8 \times 3 \mathrm{~mm}^{3}$ was harvested after the period of 2 weeks. The grown crystal of GRC is shown in figure 7.

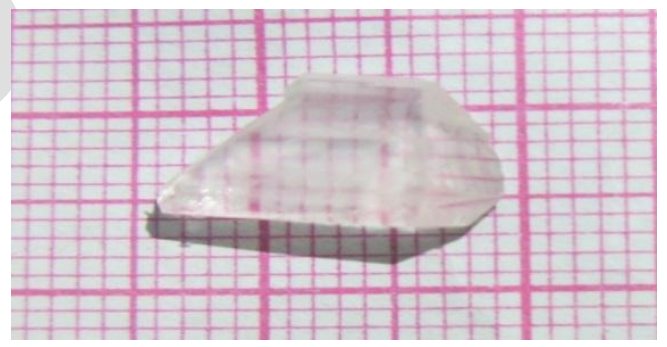

Fig.7. Photograph of GRC single crystal

\subsection{Single crystal $X$-ray diffraction}

Single crystal XRD studies were carried out to identify the cell parameters using an ENRAF NONIUS CAD4 automatic X-ray diffractometer. The lattice parameters are estimated 
to $\mathrm{be} a=7.023$ (8) $\AA, \mathrm{b}=12.179$ (10) $\AA, \mathrm{c}=5.469$ (8) $\AA, \alpha=\beta=\gamma=90^{\circ}$,Volume = 467.9(9)

$\AA^{\wedge} 3$ and hence the crystal belongs to orthorhombic crystal system.

\subsection{Powder X-ray diffraction}

The powder X-ray diffraction analysis was carried out to cnnfirm the crystallinity and also to ascertain the purity of the grown GRC crystal. The powder sample of GRC was subjected to powder XRD analysis and the recorded pattern is shown in figure 8. The sharp peaks indicate the crystallinity of the grown crystal.The spectrum was indexed using TREOR software package.

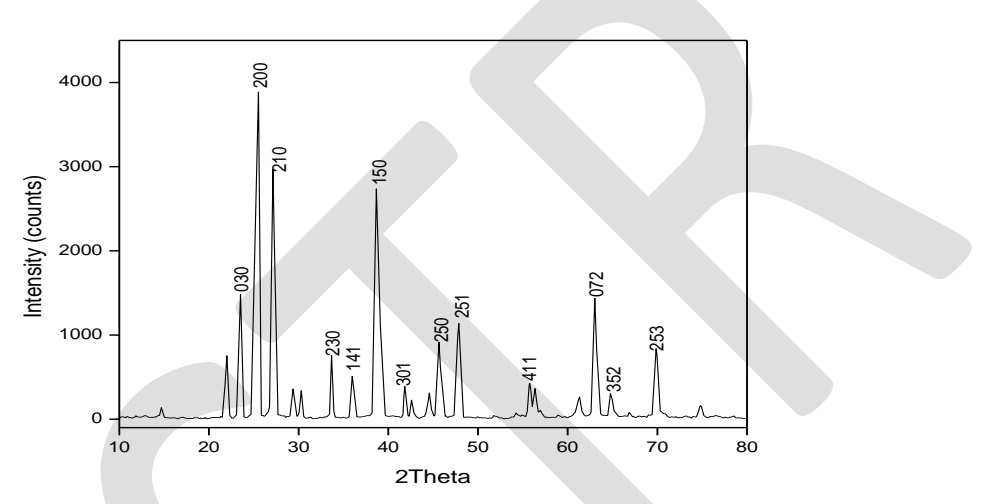

Fig.8. Powder XRD pattern of GRC crystal

\subsection{Optical Studies}

The transmission range and cut-off wavelength of single crystals are important factors for optical applications. To find the transmission range of GRC, the optical transmission spectrum of the GRC for the wavelength between 190 and $1100 \mathrm{~nm}$ was recorded using Perkin Elmer Lambda UV-Vis-NIR spectrometer. The transmittance spectrum ofGRC crystal is shown in Figure 9.For this study, optically transparent, cut and polished single crystal of thickness $1 \mathrm{~mm}$ is used. From the transmission spectrum, it is observed that the crystal has good transmission in the entire visible and IR region and the lower cutoff wavelength of the GRC is $318 \mathrm{~nm}$, this suggests that the material is quite suitable for SHG generation and related optoelectronic applications [22]. The absorption coefficient $(\alpha)$ was calculated from transmittanceusing the following relation

$$
\alpha=\frac{1}{d} \log (1 / \mathrm{T})
$$

Where $\mathrm{T}$ is the transmittance and $\mathrm{d}$ is the thickness of the crystal. The optical band gap of the GRC single crystal was determined from the absorption spectrum [23] using the near-band edge absorption relation

$$
(\alpha \mathrm{h} v)^{\mathrm{n}}=\mathrm{A}\left(\mathrm{h} v-\mathrm{E}_{\mathrm{g}}\right)
$$


Where $\mathrm{A}$ is the optical transition dependent constant, $\mathrm{E}_{\mathrm{g}}$ is the optical energy band gap, $v$ is the frequency of incident beam, $\mathrm{h}$ is the Planck's constant, $\mathrm{n}$ is the characterizes the transition. For direct allowed and forbidden transitions, $\mathrm{n}=2$ and $2 / 3$ respectively, and for indirect allowed and forbidden transitions $n=1 / 2$ and $1 / 3$ respectively.

The analysis of equation (13) showed that, $n=2$ and $1 / 2$ fitted for the as grown GRC single crystals sample confirming direct and indirect allowed transition. Figure 10(a) shows the plot of $(\alpha h v)^{2}$ against hv and 10(b) shows $(\alpha h v)^{1 / 2}$ against hv [24] for GRC crystals. The intercept of the straight line on the photon energy axis gives the direct band gap value of $3.9326 \mathrm{eV}$ and indirect band gap value of $5.0140 \mathrm{eV}$.

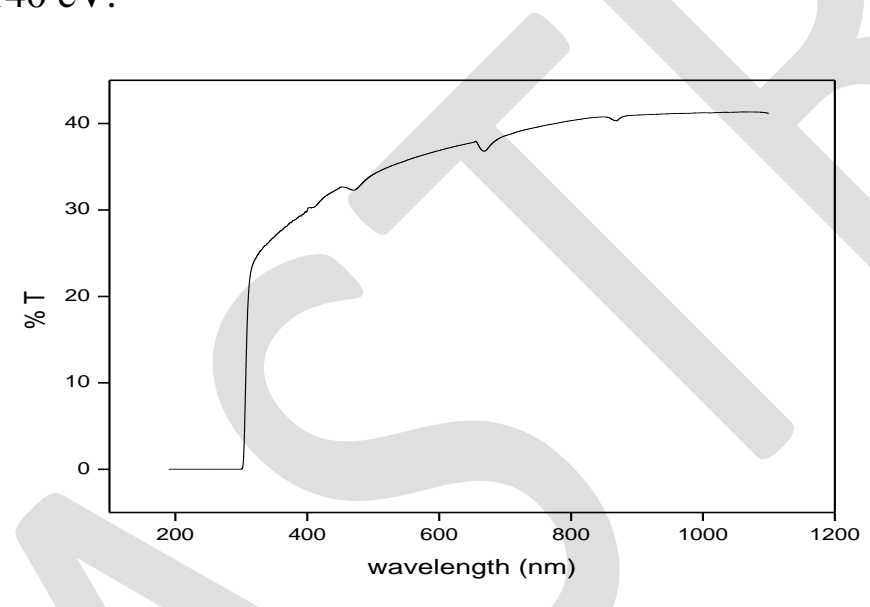

Fig.9. UV-Vis-NIR spectrum of GRC crystal

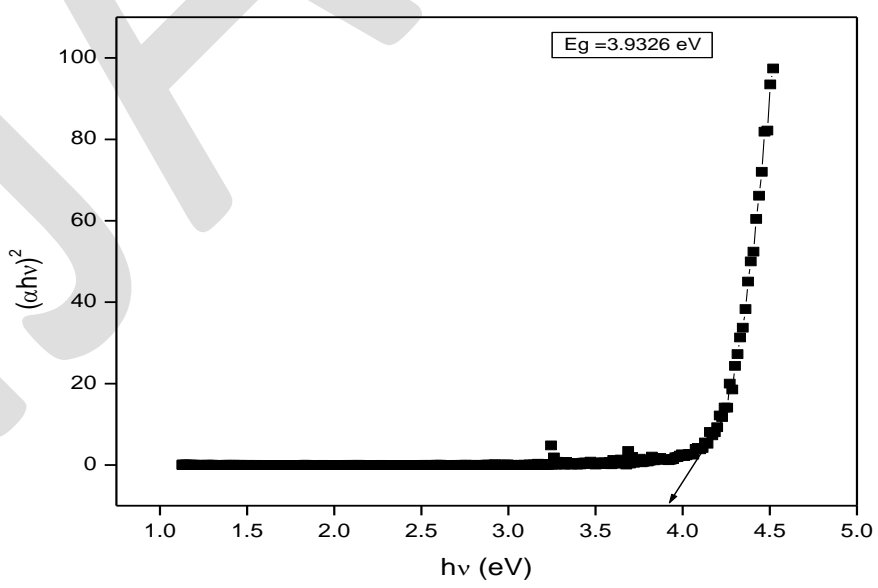

Fig.10a. Plot of $(\alpha h v)^{2}$ versus hv giving direct band gap of GRC crystal 


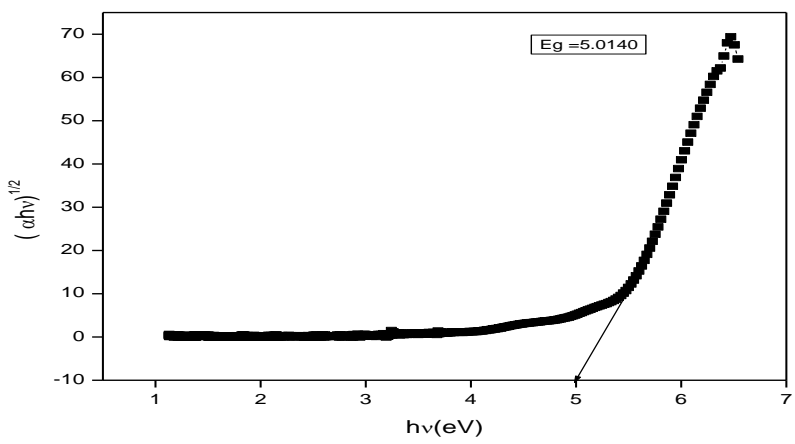

Fig.10b. Plot of $(\alpha h v)^{1 / 2}$ versus hv giving indirect band gap of GRC crystal

\subsubsection{Determination of optical constants}

The optical acrimony of materials is essential to determine its performance inoptoelectronic devices [25]. Measurement of the refractive index is vital for frequency doubling experiments and in appraisement of optical parameters when employing NLO crystals. The optical properties may be too closely relevant to the material's atomic structure, electronic band structure and electrical properties [25]. The diverse optical constants were also calculated cashing the following theoretical formulae [26]. Extinction coefficient (K) can be determined from the equation as follows,

$$
\mathrm{K}=\lambda \alpha / 4 \pi
$$

Where, $\lambda$ is the wavelength of the ultraviolet radiation. The reflectance $(\mathrm{R})$ in terms of absorption coefficient and refractive index (n) can be written as [27],

$$
\begin{array}{r}
\mathrm{R}=1 \pm \frac{\sqrt{(1-\exp (1-\alpha t)+\exp (\mathrm{\alpha} t)}}{1+\exp ((-\alpha t)} \\
\mathrm{n}=-\frac{(R+1) \pm \sqrt{3 R 2+10 R-3}}{2(R+1)}
\end{array}
$$

$(\mathrm{K}, \mathrm{R})$ as a function of photon energy and refractive index as function of wavelengthare plotted in the Figs. 11, 12 and 13. From these plots, it is known that the refractive index decreases with the increase of wavelength. The high transmission, low extinction coefficient and low refractive index of crystals in the UV-VIS region makes the GRC material a prominent one for antireflection coating in solar thermal devices. The calculated refractive index (n) is 1.2174 for the GRCcrystal at $400 \mathrm{~nm}$. High optical transparency, low absorbance, low reflectance and low 
refractive index of GRC in the UV-visible region concocts that the material as a vital one for antireflection coating in solar thermal devices and NLO applications [28].

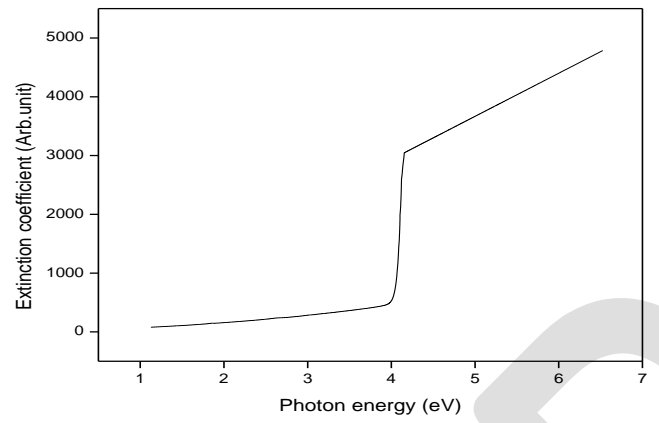

Fig.11.Plot of extinction coefficient (K) vs. photon energy

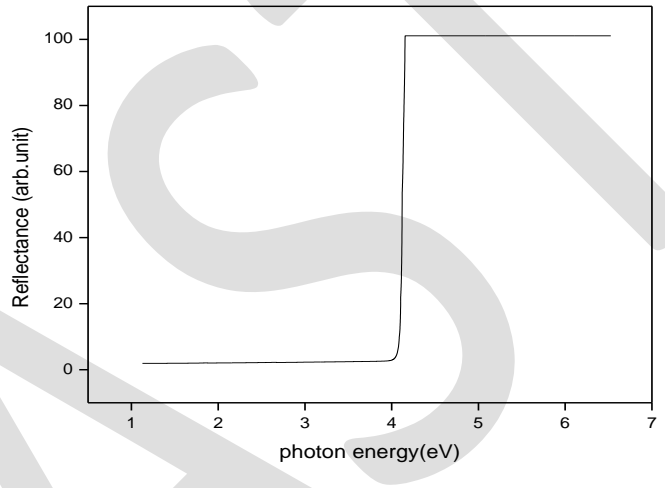

Fig.12.Plot of reflectance (R) vs. photon energy

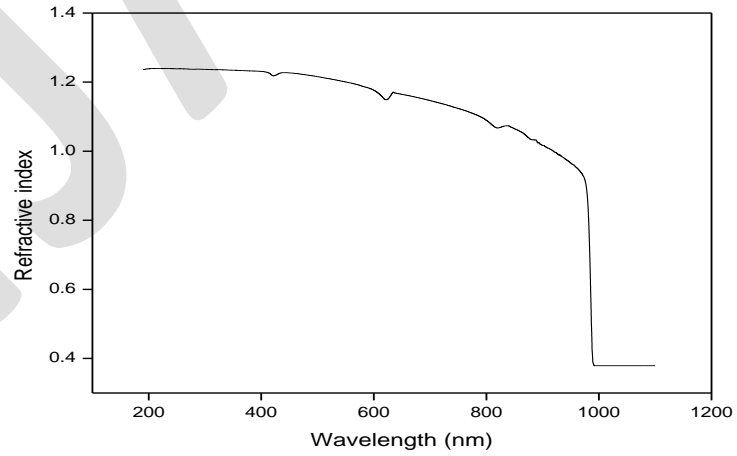

Fig.13. Variation of refractive index with wavelength

The photonic response of optical conductivity $\left(\sigma_{\mathrm{op}}\right)$ of the material when irradiated with light is relevant to the refractive index (n) and the speed of light (c) as follows 


$$
\sigma_{\text {op }}=\frac{\alpha \mathrm{nc}}{4 \pi}
$$

and also the electrical conductivity is correlated to the optical conductivity of theGRC crystal as follows,

$$
\sigma_{\mathrm{e}}=\frac{2 \lambda \sigma o p}{\alpha}
$$

Fig.14 deduce that the optical conductivity increases with photon energy, having highmagnitude $\left(10^{10}(\Omega \mathrm{m})-1\right)$ and electrical conductivity $\left(10^{8}(\Omega \mathrm{m})-1\right)$ supports semiconducting nature of the material [29]. From Fig.15 it suggests that the low extinction value $\left(10^{-5}\right)$, hence this material make more germane for device applications in computing ultrafast optical data [30]. The electric susceptibility $(\chi c)$ is closely connected to optical constants given by [31],

$$
\begin{aligned}
& \varepsilon_{\mathrm{r}}=\varepsilon_{0}+4 \pi \chi_{\mathrm{c}}=\mathrm{n}^{2}-\mathrm{K}^{2} \\
& \chi_{\mathrm{c}}=\frac{\mathrm{n} 2-\mathrm{K} 2-\varepsilon 0}{4 \pi}
\end{aligned}
$$

where $\varepsilon 0$ is the dielectric constant in absence of any contribution from free carriers. Thecalculated value of electric susceptibility $(\chi c)$ is 0.2433 at $\lambda=400 \mathrm{~nm}$. The real part $\left(\varepsilon_{\mathrm{r}}\right)$ and imaginary part $\left(\varepsilon_{\mathrm{i}}\right)$ of the dielectric constants can be evaluated using the relations [31],

$$
\varepsilon_{\mathrm{r}=\mathrm{n}^{2}}-\mathrm{K}^{2} \text { and } \varepsilon_{\mathrm{i}}=2 \mathrm{nK}
$$

The real and imaginary parts of the dielectric constant of the grown crystal were determined and shown in figure 15. From the graph, both real and imaginary part of dielectric constant increases with increase of photon energy. Both dielectric constants are maximum at $6.2 \mathrm{eV}$ photon energy. The lower value of dielectric constant with wide band gap of GRC crystal suggests the suitability of optoelectronic devices.

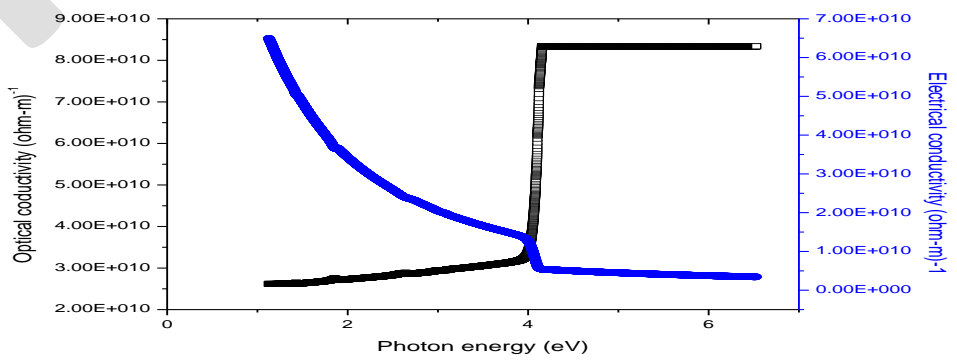

Fig.14. Variation of optical conductivity and electrical conductivity vs. photon energy 


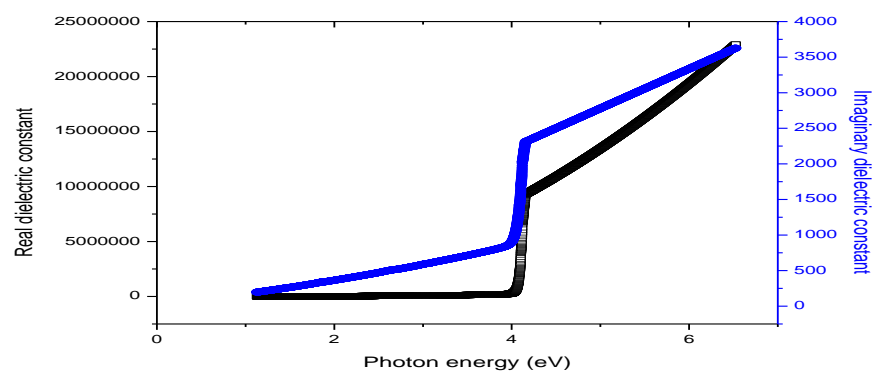

Fig.15. Variation of real and imaginary dielectric constant with photon energy

\subsection{Photoluminescence (PL) studies}

Photoluminescence (PL) spectroscopy is one of the effective tools in probing the electronic energy band structure of material and also it provides the tidings of different energy states available between the valence band and conduction band authentic for radioactive recombination [32]. Basically, observation of photoluminescence at a certain energy can be viewed as an indication that excitation populated an excited state associated with this transition energy. Photoluminescence spectrum was recorded using PERKIN ELMER LS 45 spectrofluorophotometer and excitation source used was xenon arc lamp (150 W). An extensive photoluminescence emission spectrum occurs in the range $275-500 \mathrm{~nm}(4.50-2.48 \mathrm{eV})$ as clearly observed in Fig. 16. The PL spectrum exhibited a peak at about $418 \mathrm{~nm}(2.96 \mathrm{eV})$ which can be attributed to the donation of proton from carboxylic acid to amino group in grown crystal. It also revealed that the fluorescence peaked at violet region.Hence we can convict that the photoluminescence of violet emissionis found to play a decisive role in OLED applications [33].

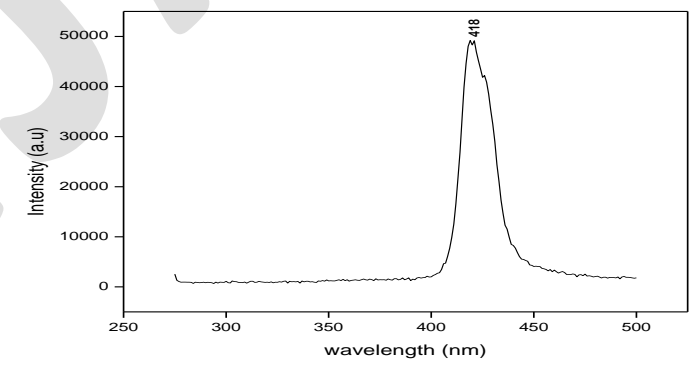

Fig.16. Photoluminescence emission of GRC

\subsection{Second harmonic generation test}

Second harmonic generation (SHG) is also called a frequency doubling in nonlinear optics in which photons interacting with a nonlinear material are effectively combined to form 
new study of NLO efficiency has been carried out by modified experimental set up of Kurtz and

Perry [34]. The crystal was grind into a homogenous powder and densely packed between two transparent glass micro capillary tubes. An intensity of Nd: YAG laser $(\lambda=1064 \mathrm{~nm})$ with input pulse of $1.9 \mathrm{~mJ}$ was passed through an IR reflector and then directed on the micro crystalline powdered sample packed in a capillary tube. The SHG behavior was confirmed from the output of the laser beam having green light emission. The second harmonic output signal of $89 \mathrm{mV}$ was obtained for GRC. The output signal obtained for the reference material was $75 \mathrm{mV}$ for the same input pulse of $1.9 \mathrm{~mJ}$. Thus the relative measured output from the sample with respect to KDP crystal shows that SHG efficiency of the GRC crystal is 1.1866 times as that of the KDP crystal. Thus the grown GRC sample has good NLO property.

\subsection{TG/DTA analysis}

The thermo gravimetric analysis (TGA) and the differential thermal analysis (DTA) give information regarding phase transition and different stages of decomposition of the crystal system [35]. The TG/DTA curves for GRC crystal were recorded for the range of temperature from $40-750^{\circ} \mathrm{C}$ in nitrogen atmosphere at the heating rate of $10^{\circ} \mathrm{C} / \mathrm{min}$ using the instrument Perkin Elmer STA 6000 thermal analyzer. The initial mass of the material was taken to be 9.460 $\mathrm{mg}$. The thermo gravimetric analysis and differential thermal analysis (TG/DTA) of GRC crystal are displayed in Fig.17. The sample is stable up to $222^{\circ} \mathrm{C}$. The grown crystal GRC exhibits a single stage of decomposition. The first weight loss occurs at $233^{\circ} \mathrm{C}$. The decrease in mass may be due to the thermal decomposition of elements present in the sample. The DTA trace of GRC shows that, there is a sharp endotherm matching with the decomposition of GRC. This shows that the grown crystal is thermally stable and makes it suitable for possible applications in lasers where the crystal is required to withstand high temperatures.

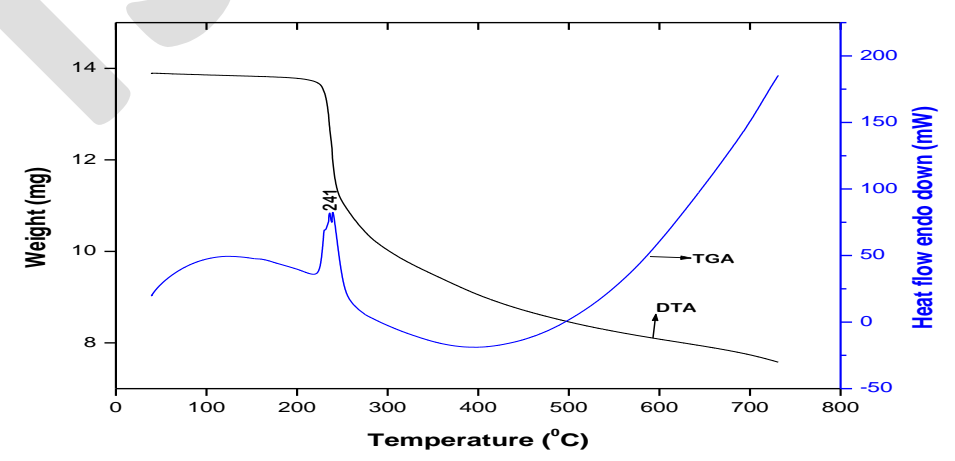

Fig.17. TG/DTA thermal curves for GRC crystal 


\subsection{Fourier transform spectral analysis}

To confirm the presence of glycine in zwitterionic form inGRC and to analyze qualitatively the presence of the functional groups in the grown crystals, the FTIR spectra ofGRC crystal was recorded between $4000 \mathrm{~cm}^{-1}$ and $400 \mathrm{~cm}^{-1}$. Fig. 18represents the FTIR spectra of BGRC crystal. Free glycine, the simplest amino acid exists in neutral zwitterionic phase as $\mathrm{NH}_{3}^{+}-\mathrm{CH} 2-\mathrm{COO}-$ in which the amino group exists as ammonium ion $\left(\mathrm{NH}^{+}\right)$and the carboxyl group exists as carboxylate ion (COO-). Amino acids in the form of zwitterions do not show $\mathrm{N}-\mathrm{H}$ stretching at $3200 \mathrm{~cm}-1$ but show a broad band with multiple peaks between 3600 $\mathrm{cm}-1$ and $2600 \mathrm{~cm}-1$ assigned to asymmetric stretching of $\mathrm{NH}^{+}{ }^{+}$group [36]. In GRC crystal, same mode can be seen from $3110 \mathrm{~cm}^{-1}$ to $2567 \mathrm{~cm}^{-1}$. The principal frequencies for the ionic groups in glycine are $1610 \mathrm{~cm}^{-1}, 694 \mathrm{~cm}^{-1}, 607 \mathrm{~cm}^{-1}$ and $504 \mathrm{~cm}^{-1}$ for the COO- ion. In GRC crystal, these modes occur at $1599 \mathrm{~cm}^{-1}, 693 \mathrm{~cm}^{-1}, 510 \mathrm{~cm}^{-1}$. For the $\mathrm{NH}^{+}$group, the characteristic frequencies are observed at $1585 \mathrm{~cm}^{-1}, 1492 \mathrm{~cm}^{-1}, 1131 \mathrm{~cm}^{-1}$. In GRC, these modes are found at $1599 \mathrm{~cm}^{-1}, 1501 \mathrm{~cm}^{-1}, 1128 \mathrm{~cm}^{-1}$, confirming the existence of glycine zwitterions which facilitates the formation of complexes of glycine. The sharp peaks at $896 \mathrm{~cm}^{-1}$ and 938 $\mathrm{cm}^{-1}$ are assigned to the stretching vibrations of NO3. The absorption peaks at $510 \mathrm{~cm}^{-1}$ may also be attributed to modes implicating the alkaline cation namely $\gamma(\mathrm{ONa}+)$ carboxylate - sodium ion stretching mode. The frequency assignment for the various absorption peaks observed in FTIR spectra for GRC crystal are tabulated in table 2.

Table 2: Spectral Assignments forGRC crystal

\begin{tabular}{|l|l|}
\hline Wave number $\left(\mathrm{cm}^{-1}\right)$ & \multicolumn{2}{|c}{ Assignments } \\
\cline { 1 - 2 } GRC crystal & \multirow{2}{*}{$\mathrm{NH}_{3}{ }^{+}$stretching } \\
\hline 3110 & $\mathrm{OH}$ stretching \\
\hline 2567 & $\mathrm{NH}_{3}{ }^{+}$symmetric bending \\
\hline 1599 & $\mathrm{C}-\mathrm{C}$ stretch \\
\hline 1501 & $\mathrm{C}-\mathrm{O}-\mathrm{O}$ symmetric stretching \\
\hline 1395 & $\mathrm{C}-\mathrm{O}-\mathrm{O}$ symmetric stretching \\
\hline 1339 & $\mathrm{NH}_{3}{ }^{+}$rocking \\
\hline 1128 & $\mathrm{CH}_{2}$ rocking \\
\hline 938 & $\mathrm{C}-\mathrm{C}-\mathrm{N}$ symmetric stretching \\
\hline 896 & $\mathrm{C}-\mathrm{O}-\mathrm{O}$ bending \\
\hline 679 & C-C-O bending \\
\hline 510 & \\
\hline
\end{tabular}




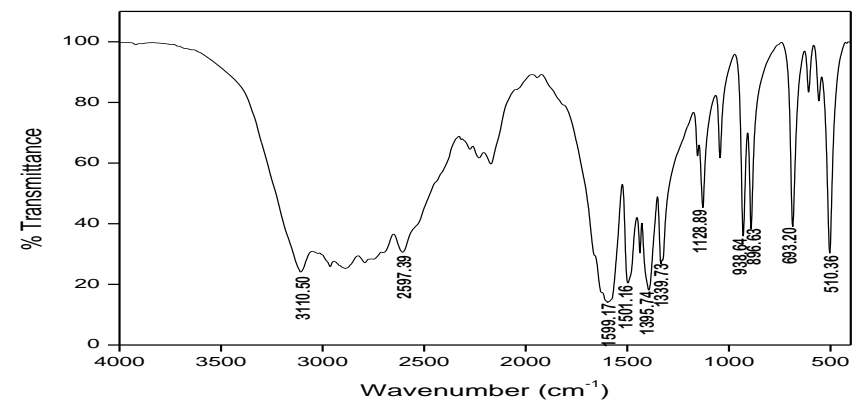

Fig.18. FTIR spectrum of GRC crystal

\subsection{Mechanical characterization}

Hardness of the material carries information about the strength, molecular bindings,yield strength and elastic stiffness constant [37-39]. The mechanical strength of the materials plays a significant key role in device fabrication. The hardness measurement on a crystalprovides information about the elastic, plastic, viscous and fracture properties. The Vickersmicrohardness measurement convicts the mechanical property of grownGRC crystal.The microhardness test was carried out at room temperature and loads of alternatemagnitudes such as 25, 50 and $100 \mathrm{~g}$ were applied. For a specified load at least five well-definedimpressions were referred and the average of the all the diagonals (d) wereconsidered. The Vickers microhardness number is calculated using the expression,

$$
\mathrm{Hv}=1.855 \mathrm{P} / \mathrm{d}^{2}
$$

whereHvis Vickers hardness number in $\mathrm{kg} \mathrm{mm}^{-2}, \mathrm{P}$ is the indenter load in $\mathrm{kg}$ and $\mathrm{d}$ is thediagonal length of the indented impression in mm [40]. Fig.19 exhibits the variation ofhardness number (Hv) as an event of applied load ranging from 25-100 $\mathrm{g}$ for GRC crystal. It is noted from the figure that hardness (Hv) increases with increasing appliedindentation load, which can be considered as the reverse indentation size effect (RISE)[41-43].

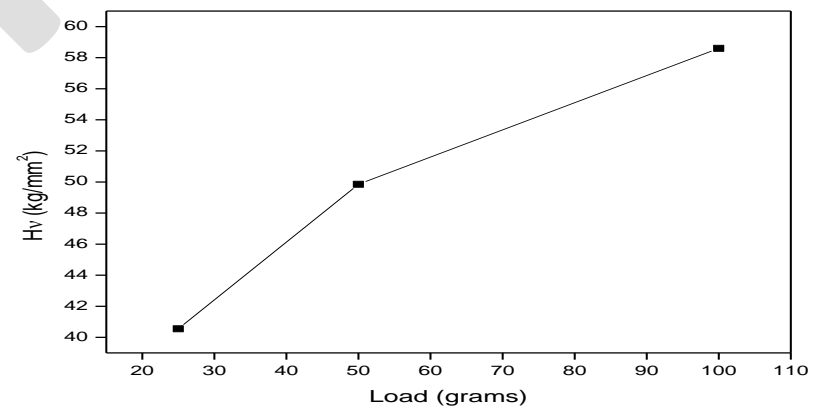

Fig.19. Variation of hardness number with load for GRC crystal 
The size of indentation and load are relevant through Meyer's law [44],

$$
\mathrm{P}=\mathrm{ad} \mathrm{d}^{\mathrm{n}}
$$

wherea is the standard hardness constant and ' $\mathrm{n}$ ' the Meyer's index also known as workhardening coefficient. The value of work hardening coefficient (Meyers index number) ' $n$ ' isevaluated from the graph plotted between $\log \mathrm{P}$ vs $\log \mathrm{d}$ and is shown in Fig.20. Theslope of the straight line of graph gives the value of ' $n$ ' evaluated as 2.65336. For the regular ISE behavior we have $n<2$. When $n>2$, there is a reverse ISE behavior. This is in good consent with the experimental data and thus confirms the reverse ISE behavior. According toOnitsch [44], Meyers index ' $\mathrm{n}$ ' should lies between 1 and 1.6 for hard materials and above1.6 for soft materials. Hence GRC can be labeled under the category of soft materials.

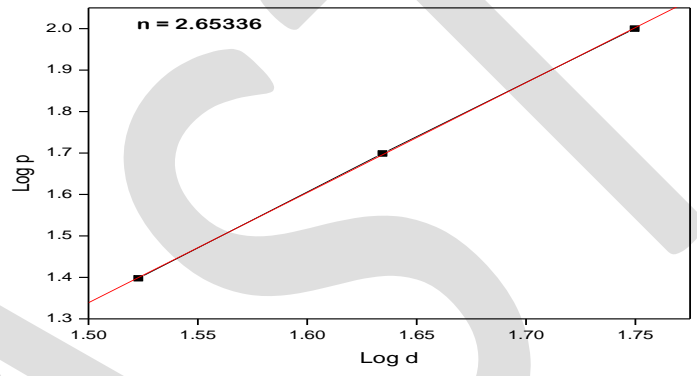

Fig.20. Plot of $\log (\mathrm{P})$ versus $\log (\mathrm{d})$ for GRC crystal

Using Hv and Mayer's index value (n), the yield strength ( $\sigma \mathrm{y})$ (Fig.21) can bemeasured by following relation [45].

$$
\sigma_{\mathrm{y}}=\mathrm{Hv} / 3
$$

Using Wooster's empirical formula we calculated elastic stiffness constant (C11) forfollowing relation [46],

$$
\mathrm{C} 11=\mathrm{Hv}^{7 / 4}
$$

the elastic stiffness constant (C11) gives an opinion of tightness of bonding betweenneighboring atoms. A graph is plotted between load Pvs.stiffness constant C11 and isrepresented in Fig.22. From the graph it clarifies that the stiffness constant increases withincrease of load. The higher value of stiffness constant $\mathrm{C} 11$ mentions that the binding forcesbetween the ions are quite strong [47]. The calculated stiffness constant C11, yield strength oyand Vickers hardness values for different load range 25-100 $\mathrm{g}$ are tabulated in Table 3. 


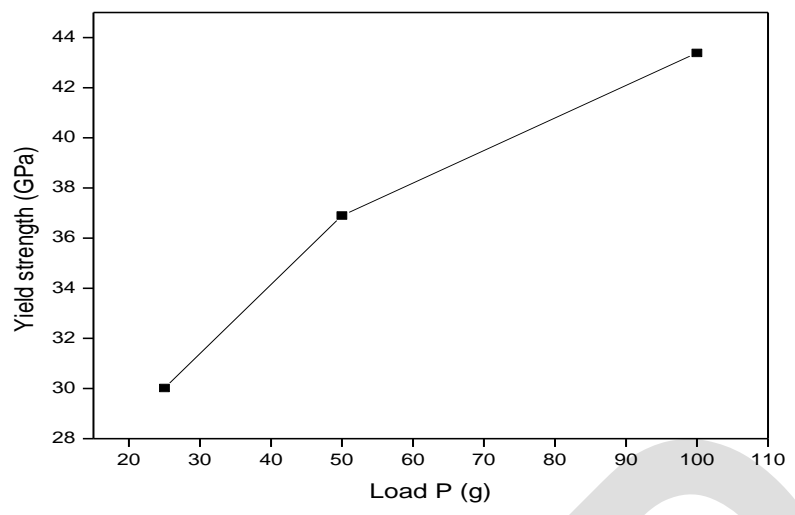

Fig.21.Variation of yield strength with load for GRC crystal

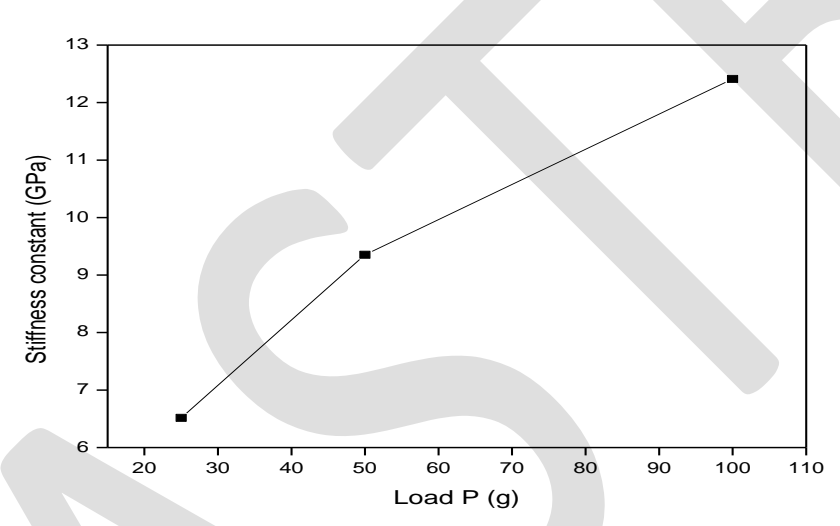

Fig.22. Variation of Stiffness constant with load for GRC crystal

Table 3.Calculated mechanical parameters of GRC

\begin{tabular}{|c|c|c|c|c|}
\hline Load P (g) & $\mathrm{Hv}\left(\mathrm{kg} \mathrm{mm}^{-2}\right)$ & Meyer's index & бy (MPa) & $\mathrm{C} 11 \times 10^{12}(\mathrm{~Pa})$ \\
\hline 25 & 40.55 & 2.65336 & 3.0020 & 6.5160 \\
\hline 50 & 49.85 & 2.65336 & 3.690 & 9.3522 \\
\hline 100 & 58.6 & 2.65336 & 4.3385 & 12.4114 \\
\hline
\end{tabular}

The resistance to fracture indicates the toughness of a material and the fracture toughness Kc determines how much fracture stress is applied under uniform loading and is given by a relation [48]

$$
\mathrm{Kc}=\mathrm{P} / \beta_{0} \mathrm{c}^{3 / 2} \text { for } \mathrm{c} \geq \mathrm{d} / 2
$$


where $\beta 0$ is a constant that depends upon the indentation geometry. For Vickers indenter $\beta_{0}$ is equal to 7.

Brittleness is an important property that affects the mechanical behavior of a material and gives an idea about the fracture induced in a material without any appreciable deformation. The value of brittleness index $B \mathrm{i}$ is computed using relation

$$
\mathrm{B}_{\mathrm{i}}=\mathrm{H} \mathrm{v} / \mathrm{Kc}
$$

The calculated values of fracture toughness and hardness value for various loads are plotted in Fig.23. The graph shows the linear relationship of the two parameters and the slope of this straight line gives the brittleness index of the sample. The brittleness index of GRC crystal is estimated as $0.35123 \times 10^{3} \mathrm{~m}^{-1 / 2}$. The low value of the brittleness index reveals the good dimensional stability of the growncrystal.

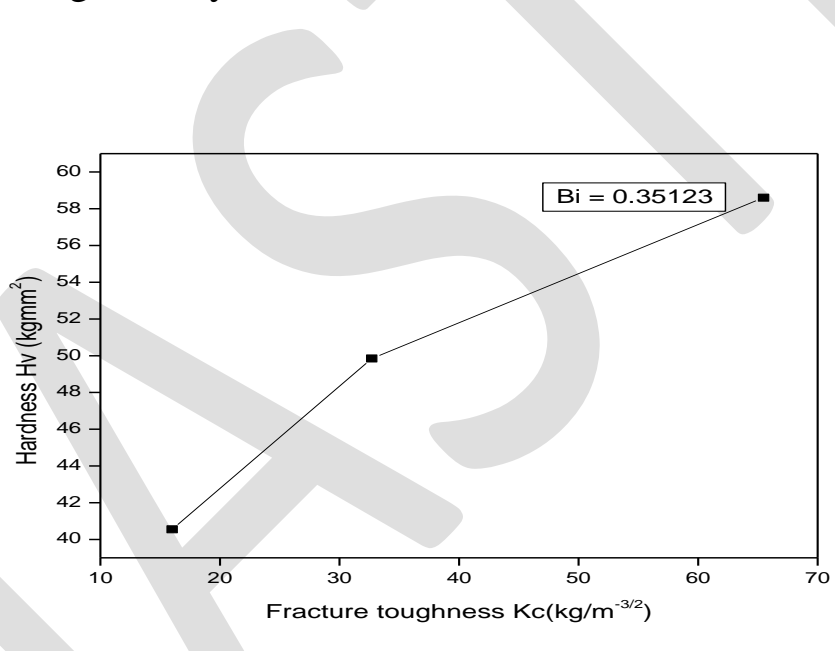

Fig.23.Plot of fracture toughness vs.hardness forGRC crystal

\subsection{SEM analysis}

In order to analyze the nature and surface morphology of the grown crystal.SEM analysis was employed. The crystal was cut into few $\mathrm{mm}$ for observing the surface morphology. The SEM images of GRC crystal taken in different magnifications are shown in Fig.24. The images show step-like growth, which suggests the existence of grain boundaries and striations. The surface is smooth and free from any visible inclusions. The micrographs also show the presence of few cracks on the crystal surface. This may be due the temperature oscillations during the crystal growth. 


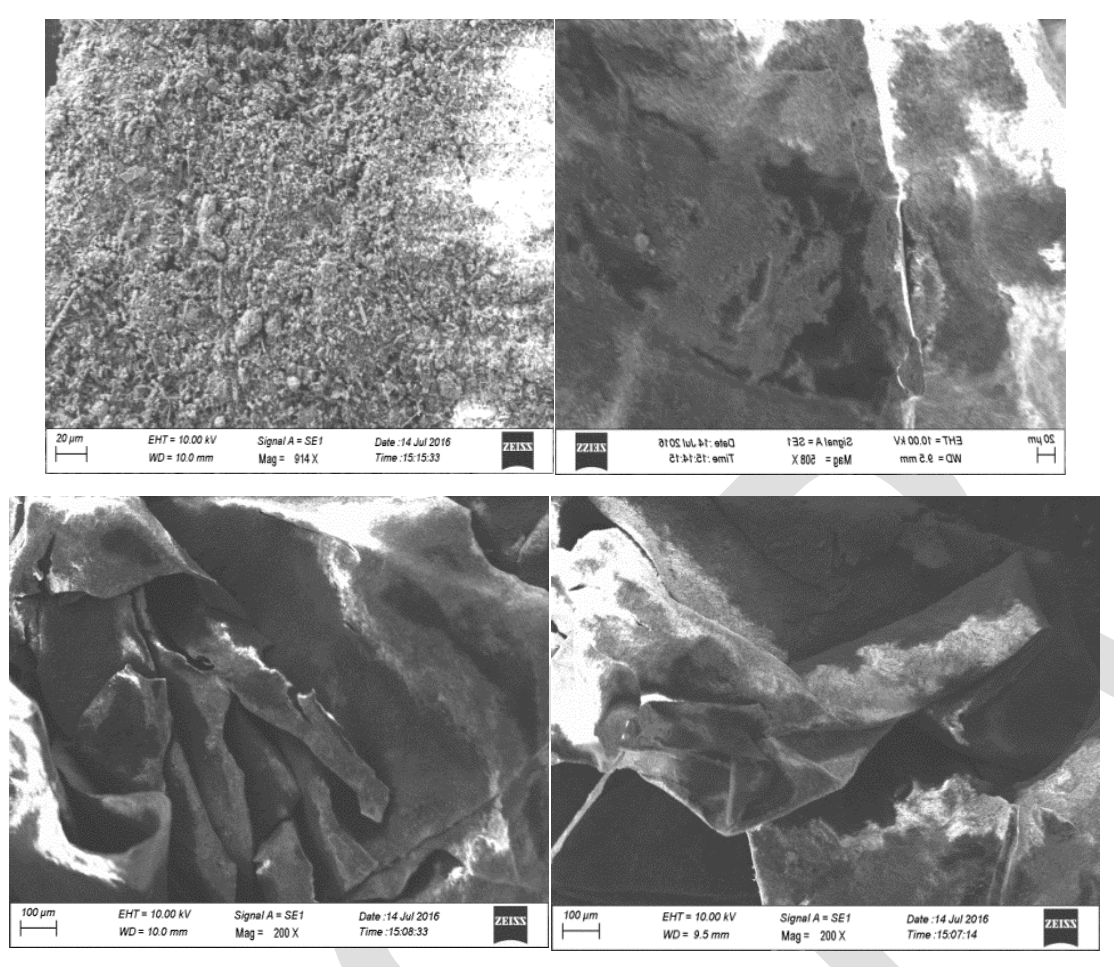

Fig.24. SEM image of GRC crystal

\subsection{Z scan measurements}

Z-scan technique is a well-known technique that allows the simultaneous measurement of both nonlinear absorptioncoefficient $(\beta)$ and the nonlinear refractive index $\left(\mathrm{n}_{2}\right)$. Due to the localized absorption of a tightly focused beam propagating through the absorbing sample, a spatial distribution of the temperature in the crystal surface isproduced. Hence a spatial variation of the refractive index is also produced.This acts as a thermal lens which results in the phase distortion of the propagating beam.Measurements of closed and open aperture of the normalized transmittance and sample position $\mathrm{z}$ have a peak to valley shapes are shown in Fig.25 (a) and 25 (b). The difference between the peak and valley transmission $\left(\Delta \mathrm{T}_{\mathrm{P}-\mathrm{V}}\right)$ is written in terms of the on axis phase shift at the focus as,

$$
\Delta \mathrm{T}_{P-V}=0.406(1-\mathrm{S})^{0.25}|\Delta \Phi|
$$

Linear transmittance aperture $(S)$ is calculated using the relation $\mathrm{S}=1-\exp \left(-2 \mathrm{r}_{\mathrm{a}}{ }^{2} / \omega_{\mathrm{a}}{ }^{2}\right)$

where $r_{a}$ is the radius of the aperture and $\omega_{a}$ is the beam radius at the aperture. The third-order nonlinear refractive index $\left(\mathrm{n}_{2}\right)$ of the crystal was calculated by the following relation $[49,50]$ 


$$
\mathrm{n}_{2}=\Delta \Phi / \mathrm{kI}_{0} \mathrm{~L}_{\text {eff }}
$$

where $\mathrm{I}_{0}$ is the intensity of the laser beam at the focus $(\mathrm{z}=0)$ and $\mathrm{k}=2 \pi / \lambda$ (where $\lambda$ is the wavelength of laser beam). The effective thickness $\left(\mathrm{L}_{\text {eff }}\right)$ can be calculated using the relation

$$
\mathrm{L}_{\mathrm{eff}}=1-\exp (\alpha \mathrm{L} / \alpha)
$$

where $\alpha$ is the linear absorption coefficient and $\mathrm{L}$ is the thickness of the sample.The nonlinear absorption coefficient $(\beta)$ can be calculated using the relation

$$
\beta=2 \sqrt{ } 2 \Delta \mathrm{T} / \mathrm{I}_{0} \mathrm{~L}_{\text {eff }}
$$

where $\Delta \mathrm{T}$ is the one peak value at the open aperture $\mathrm{z}$ - scan curve. The value of $\beta$ will be negative for saturable absorption and positive for to photon absorption process. The real and imaginary parts of the third order nonlinear optical susceptibility $\left(\chi^{(3)}\right)$ are defined as

$$
\begin{aligned}
& \operatorname{Re} \chi^{(3)}(\mathrm{esu})=10^{-4}\left(\varepsilon_{0} \mathrm{C}^{2} \mathrm{n}_{0}{ }^{2} \mathrm{n}^{2}\right) / \pi(\mathrm{cm} / \mathrm{W}) \\
& \operatorname{Im} \chi^{(3)}(\mathrm{esu})=10^{-2}\left(\varepsilon_{0} \mathrm{C}^{2} \mathrm{n}_{0}{ }^{2} \lambda \beta\right) / 4 \pi^{2}(\mathrm{~cm} / \mathrm{W}) \\
& \left|\chi^{(3)}\right|=\left[\left(\operatorname{Re} \chi^{(3)}\right)^{2}+\left(\operatorname{Im} \chi^{(3)}\right)^{2}\right]^{1 / 2}
\end{aligned}
$$

where ' $\varepsilon_{0}$ ' is the vacuum permittivity, ' $\mathrm{n}_{0}$ ' is the linear refractive index of the sample and $\mathrm{C}$ is the velocity of the light in vacuum. The obtained results from the z-scan measurements for GRC crystal are presented in table 4.

Table 4.Obtained data from Z-scan measurements for GRC crystal

\begin{tabular}{|l|l|}
\hline Laser beam wavelength $(\lambda)$ & $632.8 \mathrm{~nm}$ \\
Lens focal length & $18.5 \mathrm{~cm}$ \\
Spot size diameter in front of the aperture $\left(\omega_{\mathrm{a}}\right)$ & $1 \mathrm{~cm}$ \\
Aperture radius $\left(\mathrm{r}_{\mathrm{a}}\right)$ & $2 \mathrm{~mm}$ \\
Incident intensity at the focus focus $(\mathrm{Z}=0)$ & $3.13 \mathrm{MW} / \mathrm{cm}^{2}$ \\
Effective thickness (Leff) & $2.09 \mathrm{~mm}$ \\
Nonlinear refractive index $(\mathrm{n} 2)$ & $1.9041 \times 10^{-11} \mathrm{~cm}^{2} / \mathrm{W}$ \\
Nonlinear absorption coefficient $(\beta)$ & $1.247 \times 10^{-3} \mathrm{~cm} / \mathrm{W}$ \\
Real part of the third-order nonlinear susceptibility & $1.0197 \times 10^{-9} \mathrm{esu}$ \\
Re $(\chi(3))$ & \\
Imaginary part of the third- order nonlinear & $3.364 \times 10^{-7} \mathrm{esu}$ \\
susceptibility Im $(\chi(3))$ & \\
The third-order nonlinear susceptibility $\chi(3))$ & $3.3640 \times 10^{-7} \mathrm{esu}$ \\
\hline
\end{tabular}


The calculated value of the third order nonlinear refractive index (n2) is $1.9041 \times 10^{-11} \mathrm{~cm}^{2} / \mathrm{W}$ and the nonlinear absorption coefficient $(\beta)$ is $1.247 \times 10^{-3} \mathrm{~cm} / \mathrm{W}$. The positive value of nonlinearrefraction reveals the self-focusing nature and nonlinear absorptionco-efficient $(\beta)$ exhibits the two-photon absorption process [51]. Real and imaginary values of third order susceptibility of GRC are $1.0197 \times 10^{-9}$ and $3.364 \times 10^{-7}$ esu respectively. The absolute value of $\left(\chi^{(3)}\right)$ is $3.3640 \times 10^{-7} \mathrm{esu}$ and it is due to the $\pi$-electron cloud movement from the donor to acceptor which makes the moleculehighly polarized [52].
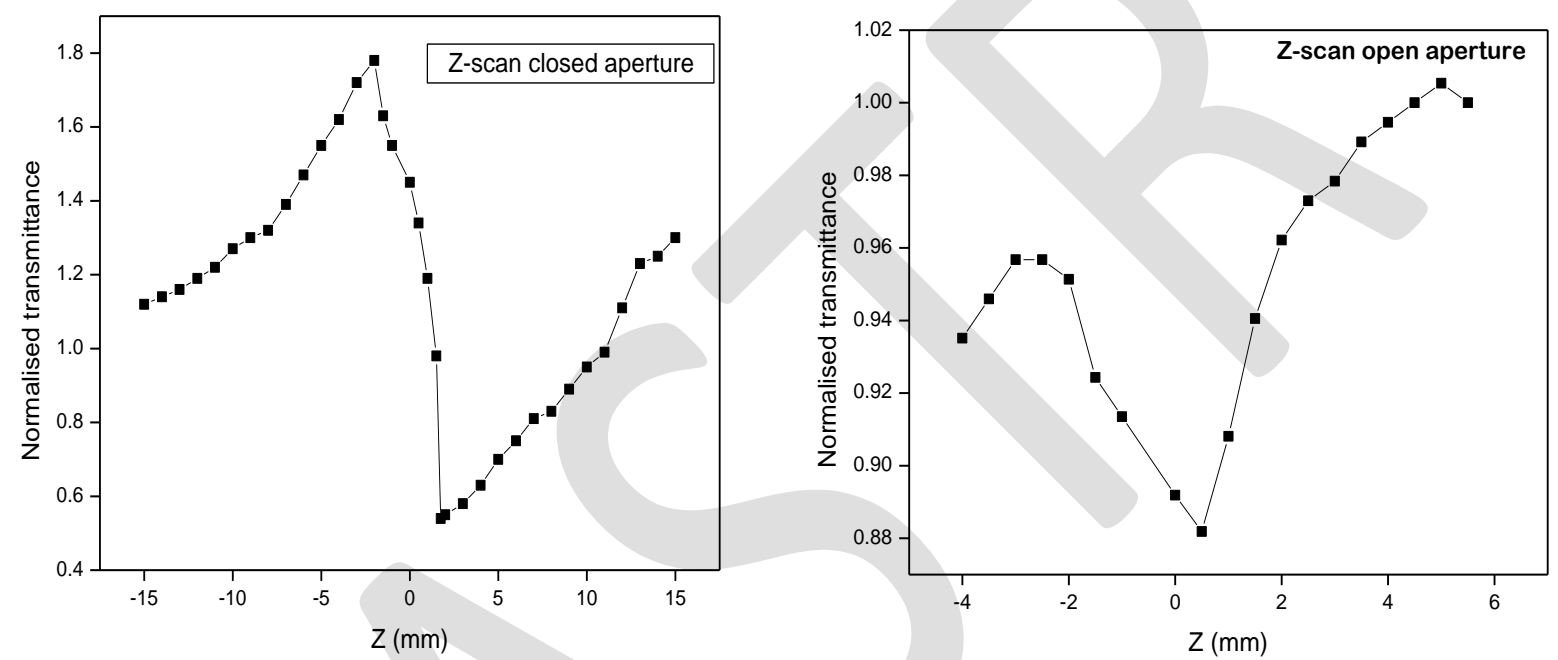

Fig.25 (a) z-scan pattern in closed aperture.(b) z-scan pattern in open aperture

\section{Conclusion}

Good quality single crystal of Glycine rubidium chloride (GRC) has been grown by slow evaporation technique and the solubility of GRC sample was estimated for water at different temperatures. Nucleation kinetics and fundamental growth parameters have also been investigated. Single crystal XRD analysis confirms the orthorhombic structure of the grown crystal.UV-Visible absorption spectrum shows excellent transmissionin the entire visible region. The band gap, refractive index, reflectance, extinction coefficient and electrical susceptibility were calculated to analyze the optical property.From themicrohardness study, we conclude that the GRC crystal belongs to a soft material category.The functional groups present in the crystal are confirmed by FTIR analysis. The powder SHG test confirms that the efficiency of GRC is nearly 1.1866 times as that of KDP crystals. The thermal behavior of the crystals has been investigated by TGA and DTA analysis. Photoluminescence spectralanalysis revealed the 
electron excitation in as-grown GRC crystal.Nonlinear refractive index, absorption co-efficient and third order susceptibility were measured by Z-scan technique.By these concerns, the GRC crystal could be apromising and a competitive candidate for future photonic device.

\section{References}

[1] J. Uma Maheswari, C.Krishnan, S.Kalyanaraman and P.Selvarajan., Mater. Res.Express 3(2016)105101

[2] S. Selvakumaret.al.,J.Mater.Chem. andPhy. 103 (2007a) 153

[3]M. Narayan Bhat, and S.M. Dharmprakash, J. Crystal Growth. 236 (2002a) 376

[4] G.S. Prasad, M. Vijayan, ActaCrystallogr.C, 47 (1991) 2603

[5]T. Uma Devi, N. Lawrence, R. Rameshbabu, S. Selvanayagam, Helen Stoeckli-Evans,

G. Bhagavannarayana, K. Ramamurthi.jmmce9( 2010) 495-507

[6] P. Paramasivam, C. Ramachandra Raja.,Journal of Crystallization Process and Technology, 1(2012) 21-24

[7] A.Jegatheesan, G.Rajarajan., International Journal of ChemTech Research,8 (2015) 572-578

[8] R. Vasanthakumari, W. Nirmalaand R. Santhakumari,Advances in Applied Science Research, 6 (2015) 159-163

[9] S.Nazarath Begum, U.Sankar, T.ChithambaraThanu and P.Selvarajan.,Otik 125 (2014) 14931497

[10]S. Janarthanan, R. Sugaraj Samuel, Y.C. Rajan, P. Suresh, K. ThangarajSpectrochimicaActa Part A: Molecular and Biomolecular Spectroscopy 105 (2013) 34-37

[11] V. Krishnakumar, M. Rajaboopathi, R. Nagalakshmi,. Adv. Mat. Lett. 2011, 2(2), 163-169

[12] Joseph Arul Pragasam A, Madhavan J, Gulam Mohamed M, Selvakumar S, Ambujam K, and Sagayaraj P, Optical Materials, 29 (2006) 173.

[13]W.S. Wang, K. Sutter, Ch. Bosshard, Z. Pan, H. Arend,P. Gunter, G. Chapuis, F. Nicolo,Jpn. Journal ofApplied Physics, 27 (7), pp. 1138-1141, 1988

[14] C.Krishnan,P.Selvarajan,T.H.Freeda, J.Cryst.Growth 311(2008)141-146

[15] A.C.Sajikumar,SVinu and C.Krishnan, J.Therm Anal calorim 119(2015) 1047-1052

[16]W.S. Wang, K. Sutter, Ch. Bosshard, Z. Pan, H. Arend,P. Gunter, G. Chapuis, F. Nicolo,Jpn. Journal of Applied Physics, 27 (7), pp. 1138-1141, 1988

[17]NyvltR,Rychly, Gottfried J and Wurzelova J crystal Growth 6(1970) 151 
[18] K. Selvaraju, R. Valluvansi, S. Kumararaman., Materials Letters, 60(2006) 1565-1569

[19] R. Jeyasekaran, P. Dennis Christy, A.Muthuvinayagam, I. Vethapotheher, P. Sagayaraj, Archievesof Applied Research, 3 (4), pp. 83-91, 2011.

[20]D.Shanthi, P. Selvarajan, R.Jothi Mani, Optik, 125(11), pp. 2531-23537. 2014.

[21]N.Vijayan, R.RameshBabu, R.Gopalakrishnan, S.Dhanushkodi, P.Ramasamy, J. Cryst. Growth, 236, 407 (2010).

[22] R. Jothimani, P. Selvarajan, H. Alex Devadoss, D. Shanthi, Adv. OptoelectronicMater. 1(2013) 67.

[23]A.Shanthi, C.Krishnan, P.Selvarajan., J. Cryst.Growth, 393(2014)7-12

[24] S.G.Rejith, C.Krishnan.,Mat.Letters, 106(2013)87-89

[25] R. Robert, C. Justin Raj, S. Krishnan, S. Jerome Das, Physica B 405 (2010) 20-24.

[26] P.V. Dhanaraj, T. Sudan, N.P. Rajesh, Curr. Appl. Phys. 10 (2010) 1349-1353.

[27] R. Surekha, R. Gunaseelan, P. Sagayaraj, K. Ambujam, The Roy. Soc. Chem. 16 (2014) 7979-7989.

[28] V. Sangeetha, K. Gayathri, P. Krishnan, N. Sivakumar, N. Kanagathara, G. Anbalagan, J. Crys. Growth 389 (2014) 30-38.

[29] P.A. Ilenikhena, Afr. Phys. Rev. 2 (2008) 68-77.

[30] MohdAnis, R.N. Shaikh, M.D. Shirsat, S.S. Hussaini, Opt. Laser Tech. 60 (2014) 124129.

[31] W.J. Jones, W.J. Orville-Thomas, Trans. Faraday Soc. 55 (1959) 203-210

[32] P.Krishnan, K. Gayathri, P.R. Rajakumar, V.Jayaramakrishnan, S. Gunasekaran, G. Anbalagan, Spectrochim. Acta A 131 (2014) 114-124.

[33] D. Kalaivani, S. Vijayalakshmi, J. Elberin Mary Theras, D. Jayaraman, V. Joseph, Opt. Mat. 50 (2015) 87-91.

[34] S.K.Kurtz, T.T.Perry, J.Appl.Phys, 39 (1968) 3798 - 3814.

[35]F.Q.Meng, M.K.LU,Z.H.Yang and H.Zeng,Matter.Lett. 33(1998)265.

[36] L.G. Wade, Organic Chemistry, Pearson Edn., Australia, Edn. 4 (2006).

[37] K. Li, X. Wang, D. Xue, Mater. Focus 1(2012) 142-148.

[38] K. Li, P. Yang, L. Niu, D. Xue, J. Phys.Chem. A 116 (2012) 6911-6916.

[39] K. Li, X. Wang, F. Zhang, D. Xue, Phys. Rev. Lett. 100 (2008) 235504-235507.

[40] Susmita Karan, S.P. Sen Gupta, Mater. Sci. Eng.A 398 (2005) 198.

[41] K. Sangwal, Mater. Chem. Phys. 63 (2000) 145-152. 
[42] J. Gong, H. Miao, Z. Zhao, Z. Guan, Mater. Sci. Eng.A 303 (2001) 179- 186.

[43] B. Basu, N.K. Mukhopadhyay, Manisha, J. Eur. Ceram. Soc 29 (2009) 801-811.

[44] K. Sangwal, B. Surowska, P. Blaziak, J. Mater. Chem. Phys. 80 (2003) 428- 437.

[45] E.M. Onitsch, Mikroscopia 2 (1947) 131-151.

[46] V. Gupta, K.K. Bamzai, P.N. Kotru, B.M. Wanklyn, Mater. Chem. Phys. 89 (2005) 64-71.

[47] W. A. Wooster, Rep. Phys. 16 (1953) 62-82.

[48]Bamzai K K, Kotru P N, Wanklyn B M., J.Mater. Sci. Technol. 16, 405-410.

[49] T. Kanagasekaran, P. Mythili, P. Srinivasan, A.Y. Nooraldeen, P.K. Palanisamy, R. Gopalakrishanan, Cryst. Growth Des. 8 (2008) 2335-2339.

[50] E.W. Van Stryland, M. Sheik-Bahae, in: M.G. Kuzyk, C.W. Dirk (Eds.), Characterization Techniques and Tabulations for Organic Nonlinear

Materials, Marcel Dekker Inc., 1998, pp. 655-692.

[51] J.J. Rodrigues, J.L. Misogati, F.D. Nunes, R. Mendonca, S.C. Zilioc, Opt. Mater. 22 (2003) 235-240.

[52] Yun Shan Zhou, En Bo Wang, Jung Peng, Polyhedron 18 (1999) 1419-1423. 